\title{
A FEIRA VAI À UNIVERSIDADE: análises e perspectivas do projeto da Feira de Agricultura Familiar na UFRRJ/IM
}

\section{THE FAIR GOES TO THE UNIVERSITY: analyses and perspectives of the Project Familiar Agriculture Fair in UFRRJ/IM}

\author{
Mariane do Rosário Silva \\ Mestranda pelo Programa de Pós-Graduação em Geografia pela Universidade Federal Rural do \\ Rio de Janeiro, Instituto Multidisciplinar \\ marianerosario19@gmail.com
}

Edileuza Dias de Queiroz Doutora em Geografia (UFF), professora do Curso de Geografia da Universidade Federal Rural do Rio de Janeiro, Instituto Multidisciplinar edileuzaqueiroz@gmail.com

\section{Resumo}

A Feira de Agricultura Familiar do Instituto Multidisciplinar da Universidade Federal Rural do Rio de Janeiro viabiliza o fortalecimento de diversas temáticas da vida campesina Este projeto, assim como os demais projetos de Extensão Universitária, possui uma temática que deve ser valorizada e incentivada pois fortalece propostas das agriculturas alternativas, como a Agroecologia, da integração da Universidade com o Programa Nacional de Fortalecimento da Agricultura Familiar (Pronaf) atendendo suas diretrizes de acordo com a Lei 11.326, 24 de julho de 2006, de ampliação e inserção dos agricultores nas vendas de seus produtos como forma de obtenção de renda e o contato dos agricultores com o público da Universidade, conectando o espaço rural e urbano nos espaço público da Universidade, como forma de exercício da cidadania destes agricultores naquele espaço. Este relato objetiva contribuir com reflexões acerca da importância da Extensão Universitária para a tentativa da consolidação das demandas dos agricultores familiares da área da baixada fluminense. A metodologia aplicada no acompanhamento do projeto é baseada na Pesquisa-Ação (Thiollent, 2011), participando diretamente de todos os processos de construção e manutenção deste projeto. Os resultados indicam a necessidade da interação da comunidade universitária para o êxito das propostas do projeto, revelando a importância da comunicação universitária, na ação extensora através do diálogo de saberes na Feira; e a necessidade de repensar novas estratégias de organização, vendas e integração entre os diferentes agentes participativos deste espaço.

Palavras-chave: Feira de Agricultura Familiar. Extensão Universitária. Diálogo de Saberes. Agroecologia. Espaço.

\section{Summary}

The Feira da Agriculturia Familiar of the Multidisciplinary Institute of Universidade Federal Rural do Rio de Janeiro enables the strengthening of many themes of peasant life, alternative agricultures, such as Agroecology, of the University's integration with the 
Programa Nacional de Fortalecimento da Agricultura Familiar (Pronaf) in compliance with its guidelines in accordance with the La The Feira da Agricultura Familiar of the Multidisciplinary Institute of Universidade Federal Rural do Rio de Janeiro enables the streghtening of many themes of peasent life, alternatives agricultores, as Agroecology, of University's integration with the Programa Nacional de Fortalecimento da Agricultura Familiar (Pronaf) in compliance with its guidelines in accordance with the Law11.326, july 24th of 2006, income and the contact of farmes with the University public, connecting the rural and urban space in the University public space, as a wya of exercising the citizenship of these farmers in the space. This report aims to contribute with the reflections aboutthe importance of University Extension PRogram for the attempt to consolidate the demands of Family farmers in the baixada fluminende área. The methodology applied to monitorate the Project is based on Pesquisa-Ação (Thiollent, 2011), participating directly in all construiction and maintenance processes of this Project. The results indicate the necessity of interaction of the university community for the success of the Project proposals, revealing the significance of university communication in the extension action trough the dialogue of knowledge at the Fair; and the requirement to rethink new strategies of organization, sales and integration among the diferente participatory agentes of this space.

Keywords: Family Agriculture Fair. University Extension. Dialogue of Knowledge. Agroecology. Space.

\section{Introdução}

O presente texto traz reflexões importantes sobre as contribuições do projeto de Extensão Universitária Feira da Agricultura Familiar, como mecanismo de incentivo às produções agroecológicas da Baixada Fluminense-RJ e ao fortalecimento da extensão comunicadora Universitária. A proposta do projeto é acompanhar e auxiliar o desenvolvimento da Feira no Instituto Multidisciplinar da Universidade Federal Rural do Rio de Janeiro (IM/UFRRJ) através da cooperação horizontal com os feirantes e, também, com a base científica, exercendo dessa forma a verdadeira Extensão na sociedade que Paulo Freire (1985) denomina como Comunicação.

O projeto tem como objetivos fortalecer a economia agrícola dos produtores familiares agroecológicos da zona da baixada fluminense-RJ através da promoção e consolidação das vendas de seus produtos no campus, gerando renda para os mesmos; a capacitação técnica e a organização do projeto junto aos agricultores de forma igualitária através de assembleias, exercendo assim esta Extensão-Comunicação.

O acompanhamento da feira foi feito em todas as edições, auxiliando os feirantes com a manutenção do balanço das vendas, com oficinas de capacitação sanitária, 
nutricional e rotulagem oferecidas pela Universidade, divulgação da feira e diálogo com a comunidade universitária e tem como metodologia de base a Pesquisa-Ação (Thiollent, 2011).

\section{A Agricultura Familiar e a Agroecologia na Baixada Fluminense}

A agricultura no Brasil, principalmente a partir da década de 1960, passa pelo processo de renovação baseada nos padrões da revolução verde, com o Estado fomentando e subsidiando a intensa tecnicização do campo no modelo tecnológico químico e mecânico (COSTA, 2017, p.21-22). Esse modelo agrícola causou severas mudanças no meio rural e na conservação de biomas, visto a alta concentração de terras e no avanço da fronteira agrícola do agronegócio.

Apesar do avanço deste paradigma agrícola no Brasil, em extensões territoriais e ideológicas, há outros diversos modelos de cultivo e plantio que tem amplificado adeptos e a perpetuação de agriculturas tradicionais, reproduzidas por gerações e povos. A Agricultura Familiar, no caso, diferencia-se em diversos aspectos da formação dos grupos ao longo da história, porém Buainain (2006, p.15) atenta que talvez seja um equívoco conceitual caracterizá-la apenas pelo uso majoritário da mão de obra familiar. Esta afirmação decorre das restrições e potencialidades à disponibilidade de recursos e de capacitação adquiridos variam para os agricultores familiares, assim como inserção ambiental e socioeconômica, ou seja, não se pode igualar certas realidades na agricultura familiar devido às diferenças de formação e econômicas.

Ainda de acordo com o autor supracitado, os agricultores familiares brasileiros têm sido negligenciados nas políticas públicas e somente a partir do PRONAF (Programa Nacional de Fortalecimento da Agricultura Familiar), em 1996, que foram reconhecidos como atores políticos e como sujeitos e beneficiários diretos de políticas públicas relevantes (op cit, 2006, p.16). Apenas em 2006, com a criação da Lei 11.326, 24 de julho de 2006, da qual estabelece as diretrizes para a formulação da Política Nacional da Agricultura Familiar e Empreendimentos Familiares Rurais (Pronaf), a qual delimitou os critérios dos agricultores a serem contemplados pelo Pronaf, tornando-se referência de incentivo para este tipo de agricultura. 
No caso específico do recorte espacial da Baixada Fluminense, há a necessidade e início dos incentivos governamentais para o fortalecimento da Agricultura Familiar pois apresenta essa atividade ainda resistente à urbanização desenfreada. O apoio a esse setor de produção agrícola nesta área é necessário para a movimentação monetária dos núcleos familiares agrícolas, que são os abastecedores dentro da Região Metropolitana do Rio de Janeiro.

A Agroecologia se enquadra como o ramo científico-prático que atender o princípio de sustentabilidade ambiental, social e econômica do art $4^{\circ}$ da Lei 11.326, 24 de julho de 2006. De acordo com Altieri (2004, p.23), a Agroecologia integra os princípios agronômicos, ecológicos e socioeconômicos para a compreensão e avaliação do efeito das tecnologias sobre os sistemas agrícolas e nesta ciência/prática objetiva-se trabalhar com sistemas agrícolas complexos em que as interações ecológicas e sinergismos criam a fertilidade do solo, a produtividade e a produção das culturas. A importância do conhecimento camponês sobre os ecossistemas, de acordo com o mesmo, gera estratégias produtivas de uso de solo, dentro de limites ecológicos e técnicos, e com isso a autossuficiência alimentar de determinadas comunidades da região (TOLEDO et $a l, 1975$, apud ALTIERI, p.26) pois “a sustentabilidade não é possível sem a preservação da diversidade cultural que nutre as agriculturas locais" (ibidem, p.26).

A conexão entre a Agricultura Familiar e a Agroecologia no Brasil se dá pelo estabelecimento das diretrizes para a formulação da Política Nacional de Agricultura Familiar e Empreendimentos Familiares Rurais segundo Art. $4^{\circ}$ (Lei 11.326, de 24 de julho de 2006) no qual observará para a implementação à essa política a produção agrícola com princípios baseados no respeito ao trabalhador rural, etnias, gêneros e geração, descentralização e na sustentabilidade ambiental, social e econômica. Estes princípios se confluem na produção de alimentos agroecológicos feita pelos agricultores/feirantes da Feira de Agricultura Familiar do IM/UFRRJ. Esta prática agrícola na Baixada Fluminense tem forte presença e mantêm-se mais imponente através da cooperação e das redes de solidariedade, como a Cooperativa da Feira da Roça de Nova Iguaçu e da Escolinha de Agroecologia, parceria entre a Pastoral da Terra (CPT) de Nova Iguaçu e a Empresa de Assistência Técnica Rural do Rio de Janeiro (EMATER-RIO). 


\section{A Feira de Agricultura Familiar e a Extensão Universitária no IM/UFRRJ}

A organização e preparação do projeto começou em setembro de 2017, com a inscrição e seleção dos agricultores/feirantes aptos pelo regimento deste para participar da feira. O principal requisito a ser atendido foi trabalhar com agricultura familiar nos municípios compreendidos dentro da área da Baixada Fluminense, delimitada no mapa a seguir.

Imagem 1: Mapa das unidades de produção dos agricultores entrevistados e da Feira da Agricultura Familiar da UFRRJ-IM

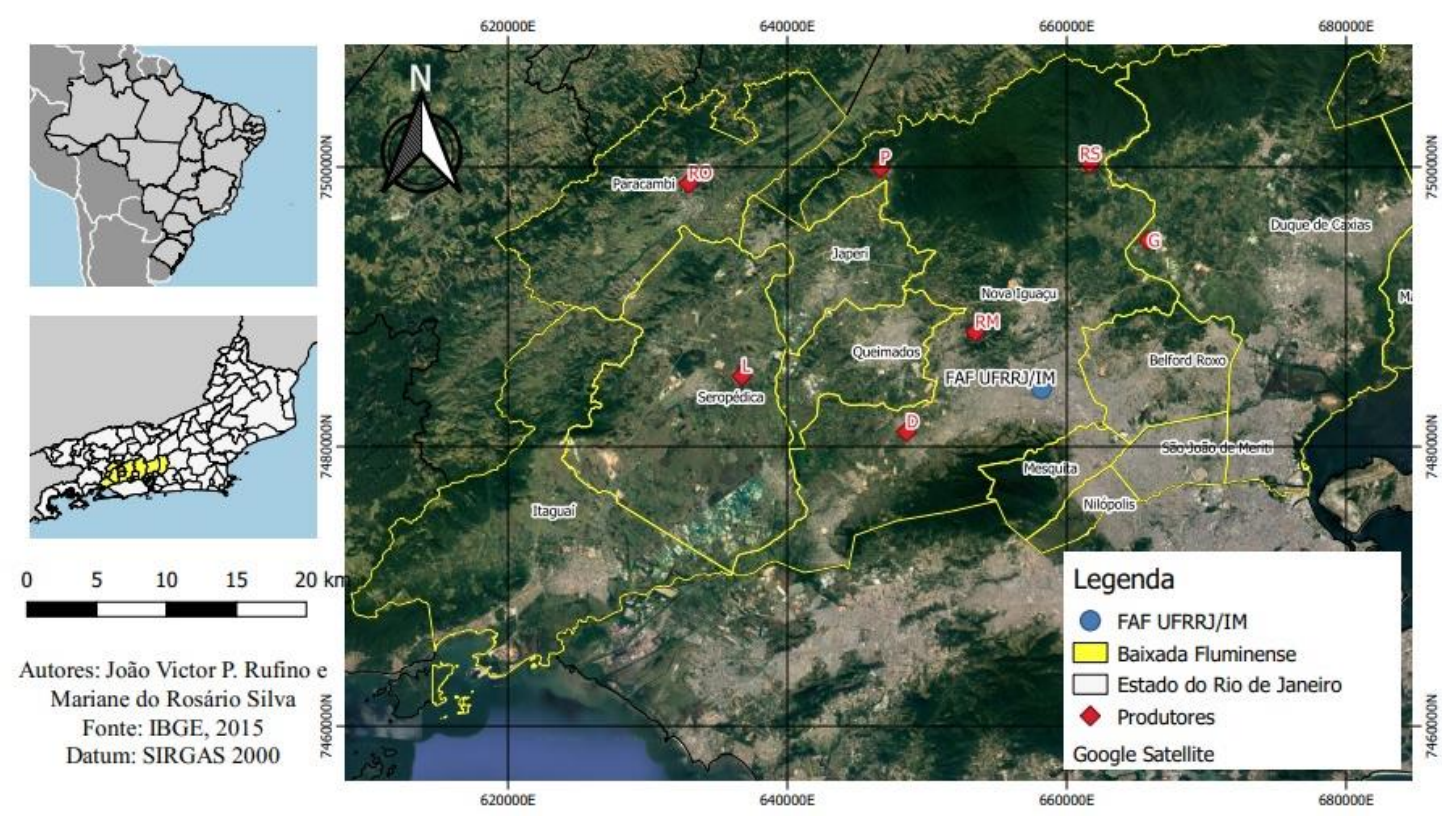

Fonte: SILVA, Mariane do Rosário.

Autores: João Victor P. Rufino e Mariane do Rosário Silva (12 de julho de 2019).

O grupo de agricultores selecionados compreende no total cinco agricultores de unidades de produção próprias e dois assentados rurais. Do total, apenas um relatou acesso recente à ajuda de custo de projetos de fomento da Agricultura Familiar e quatro compõem cooperativas, são estas Empório da Chaya, Campo Alegre, Seroorgânico e Agroindústria do Tinguá. A Feira de Agricultura Familiar do Instituto Multidisciplinar começou no dia 13 de março de 2018 com movimentação de frequentadores satisfatória e apoio do meio acadêmico como é possível ver na imagem a seguir. 
Imagem 2: Primeira Feira de Agricultura Familiar do Instituto Multidisciplinar.

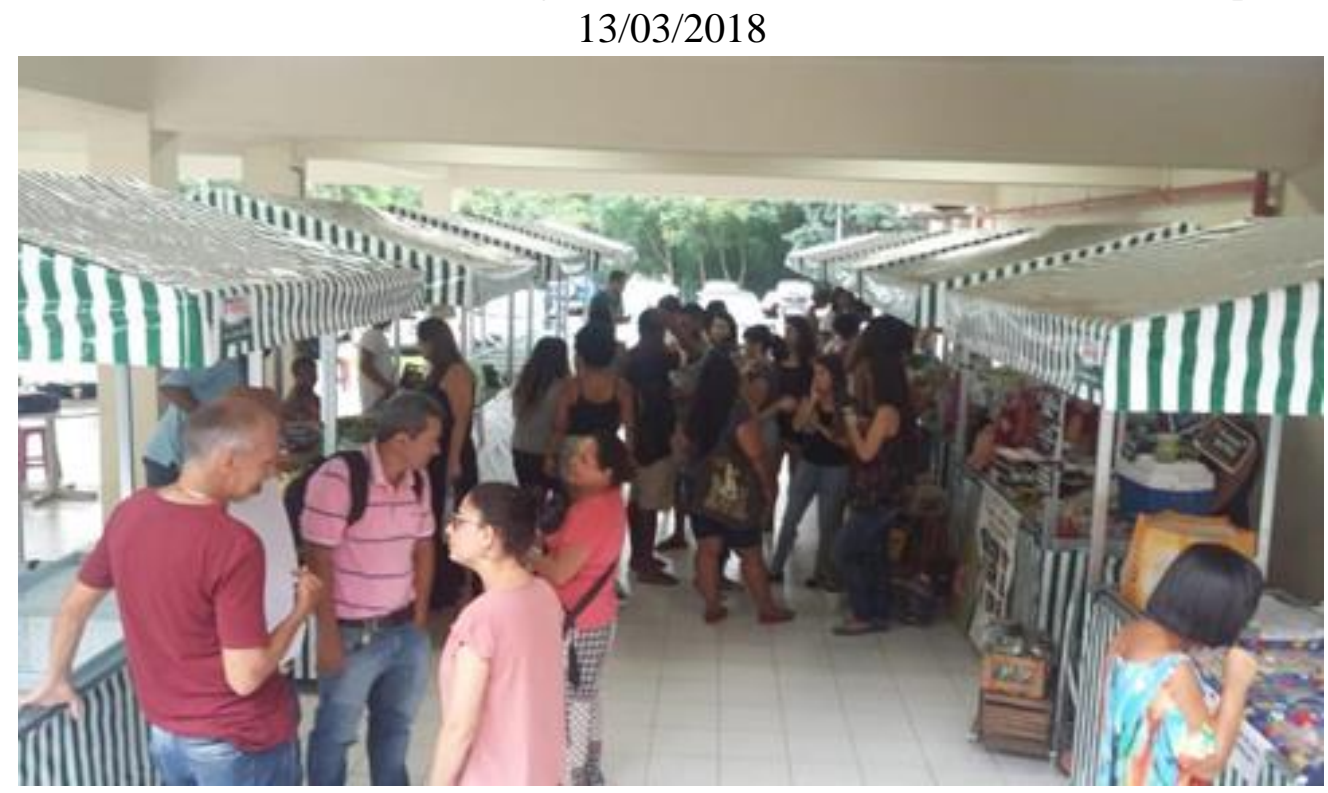

Fonte: acervo do Projeto.

O projeto procura promover, de forma horizontal e cooperativa, a Extensão Universitária através do diálogo com os agricultores/feirantes. Essa postura tem como embasamento a obra de Paulo Freire “Extensão ou Comunicação?” (1985), o qual critica a postura comum da Extensão Universitária. Segundo o autor (FREIRE, 1985, p.30-45), a Extensão age como invasão cultural, em que o conhecimento universitário invade atuando de forma messiânica e antidialógica, pressupondo a conquista e a manipulação para manter tal invasão, por ser mais prático para os extensionistas que seus "dominados" se tornem "depósitos" de seus conhecimentos de técnicas apropriadas acima de seus saberes empíricos. Diante disso, ele afirma que a Extensão deve partir do pressuposto da Comunicação, pois através dela não há sujeitos passivos e por isso “é então indispensável ao ato comunicativo, para que este seja eficiente, o acordo entre os sujeitos, reciprocamente comunicantes." (ibidem, p.45).

A vinculação do conhecimento científico, com os saberes tradicionais e ambientais, somente é possível, através da comunicação entre os agentes representativos desses conhecimentos para que a contribuição da ciência incida de modo assertivo sobre a sociedade, enfaticamente os agricultores (FREIRE, 1985). Desta forma, a Extensão do projeto trabalha as relações entre extensionistas e agricultores, em que procuramos manter a todo tempo a comunicação de forma horizontal, como é orientada também pela metodologia do projeto, a Pesquisa-Ação. De acordo com Thiollent (2011, p.20), esta 
metodologia consiste em uma pesquisa social empírica concebida e realizada em associação com uma ação ou resolução de um problema coletivo em que os pesquisadores e os participantes representativos estão envolvidos de forma cooperativa e participativa.

O projeto trabalha com a abordagem comunicativa que, de forma construtiva, a pesquisa-ação permite maior participação dos grupos em ações comunicativas, em que os discursos e conhecimentos tradicionalmente excluídos ou menosprezados para gerar informações significativas sobre suas condições ou possíveis relacionamentos com os interlocutores (op cit, 2011, p.89). Desse modo, ao decorrer das edições da feira as decisões sobre a aplicação das oficinas de capacitação para os mesmos pelos integrantes do projeto, como as oficinas de manipulação de alimentos e rotulagem já oferecidas, as datas e os horários de vendas foram decididos em reuniões e assembleias com os feirantes, onde eles discutiam e votavam a melhor alternativa a ser adotada para a execução da feira.

A feira passou por um período de experimentação do melhor horário para atrair mais frequentadores, isso ocorre devido ao esvaziamento do IM/UFRRJ em certos horários do período matutino e vespertino, principalmente no hall, local que ocorre a feira. Souza (2000) caracteriza esse fenômeno como os usos diferentes do mesmo espaço público por diferentes sujeitos, de acordo com os períodos do dia. Além disso, é a cidadania se constituindo na criação desse espaço social de luta através da instituição desta forma política neste espaço (CHAUÍ, 2001, p.12).

A ocupação democrática do espaço público da Universidade pelos feirantes é o exercício da sua cidadania e dos seus direitos em estar nele. As edições começaram quinzenalmente, testando diferentes turnos para observar a adesão da comunidade universitária com o projeto. A assembleia dos feirantes decidiu, após uma avaliação e consulta ao público, que a feira iria ocorrer a partir de junho de 2018 às terças-feiras, nos períodos da manhã e da tarde, exceto a primeira, essa reservada para as reuniões e cursos de capacitação. Após esse período de adaptação foi possível traçar um perfil da movimentação e consumo dos produtos. Nos horários típicos de aulas, no período da manhã e da tarde, e do almoço a feira esvaziava, aparecendo em sua maioria os funcionários da Universidade. Nos tempos de intervalo, manhã e tarde, a movimentação aumentava com a presença de alunos e professores. Os mais jovens procuravam comprar os produtos prontos para consumo imediato, e os mais velhos produtos diversificados. 
A conexão entre os saberes dos agricultores/feirantes e os frequentadores da feira, da teoria e da prática através através do uso do espaço público da universidade, que lhes é de direito ocupar, promovem a construção da racionalidade ambiental, que Leff (2008, p.145) denomina como saber ambiental, o qual problematiza o conhecimento fragmentado para construir caminhos de conhecimentos práticos e teóricos que rearticulem as relações sociedade-natureza. Esse conhecimento se estende além do campo de articulação das ciências para abrir-se ao terreno dos valores éticos, dos conhecimentos práticos e dos saberes tradicionais, atrelados às práticas tradicionais de manejo dos recursos naturais e às ciências e técnicas que servem de suporte às estratégias do desenvolvimento sustentável (ibidem, 150). Este saber ambiental, no caso das feiras, são enriquecidos constantemente através do diálogo de saberes entre os diferentes agentes que constroem esses espaços.

A comunicação da sociedade, não apenas da relação entre pesquisadores e pesquisados, de modo mais amplo torna-se uma ferramenta importante para a manutenção e multiplicação destes saberes. Os espaços públicos são comumente utilizados para esta ação, algo que Gomes (2012) enfatiza como lugar do diálogo permanente e trocas cotidianas. A presença das feiras nos espaços públicos são exemplos concretos para visualizar essas trocas, além de ser a fonte de renda e inserção no mercado de parcela significativa dos agricultores familiares, absorvendo os riscos da produção e do mercado e enfrentando dificuldades para se capitalizar (BUAINAIN, 2006, p.62). Por essa razão, a conquista de novos adeptos e consumidores é de suma importância para que estes produtores consigam continuar na vida campesina e fortaleçam a expressividade da luta política cotidiana dos movimentos rurais. Desta forma, o diálogo presente nas feiras entre os diferentes agentes tem atribuição importante para isto.

Apesar da permanência da feira ao decorrer do ano e a consolidação de fregueses ainda foi baixo o balanço de vendas devido ao perfil da comunidade acadêmica: majoritariamente composta por estudantes que são frequentadores do Restaurante Universitário do campus, no qual fazem suas principais refeições neste local e com pouco hábito de comprar alimentos frescos e prepará-los. Devido a isso foi decidido em assembleia entre os feirantes e os demais integrantes do projeto a elaboração das vendas de cestas de encomendas para o ano de 2019, seguindo o calendário acadêmico, com um grupo mínimo de dez compradores com o perfil principal de professores e técnicos 
universitários. Além desse projeto serão elaborados eventos da própria organização da Feira de Agricultura Familiar, com a vinculação aos eventos acadêmicos, como foi feito no dia vinte e dois de novembro de dois mil e dezoitos no evento Baixada Verde do curso de Turismo vinculado à Prefeitura Municipal de Nova Iguaçu; de oferta de oficinas, elaboração de rodas de conversas e da participação dos agricultores no recém lançado Programa de Aquisição de Alimentos do Restaurante Universitário da UFRRJ/IM.

\section{CONSIDERAÇÕES FINAIS}

A Feira de Agricultura Familiar no IM/UFRRJ é um projeto que busca renovar a Extensão Universitária da Universidade, fortalecer a Agricultura Familiar e Agroecológica da Baixada Fluminense e propiciar a Soberania Alimentar local. Através do projeto é possível preconizar a comunicação e a confluência da luta pelas demandas dos produtores locais, unificando a luta comum camponesa por direitos e melhorias para o cenário rural. A Agricultura Familiar produzida através das práticas agroecológicas garante o respeito à natureza e manutenção dos recursos naturais vitais para as gerações futuras.

Para além da mera prática comercial de compra e venda de produtos, o espaço da feira é uma forma de integrar a realidade rural com a urbana nestes espaços, de modo que se conectam e integram através do diálogo entre os diferentes agentes. Entretanto, é necessário reiterar a necessidade do diálogo da Universidade com a sociedade através de projetos como este e, deste modo, terá êxito na Extensão Universitária. Esse êxito somente será possível através da Extensão pela Comunicação entre os agricultores e pesquisadores. Além destes agentes, a adesão da comunidade universitária, estudantes, servidores e professores, é de extrema importância para a longevidade da Feira e para a contribuição para a perpetuação da atividade agrícola na Baixada Fluminense, pois a comercialização destes produtos é uma das principais formas de comprovação de renda mensal das famílias envolvidas nesse projeto.

Um possível meio para a perpetuação do projeto é o diálogo de saberes presente no espaço da feira. Através do diálogo entre os agricultores/feirantes e os frequentadores do ambiente universitário há o estreitamento dos laços entre a cidade e campo, a reflexão sobre as questões relacionadas à produção de alimentos local e sua importância para a economia da localidade. 


\section{REFERÊNCIAS}

BRASIL. Lei 11.326, de 24 de julho de 2006. Casa Civil: Subchefia para Assuntos Jurídicos. Estabelece as diretrizes para a formulação da Política Nacional da Agricultura Familiar e Empreendimentos Familiares Rurais. Disponível em: <http://www.planalto.gov.br/ccivil_03/_Ato2004-2006/2006/Lei/L11326.htm>. Acesso em: 20 de novembro de 2018.

BUAINAIN, Antônio Márcio. Agricultura familiar, Agroecologia e Desenvolvimento Sustentável: questões para debate. Brasília, DF: Instituto Interamericano de Cooperação para a Agricultura (IICA), 2006.

CHAUÍ, Marilena. Escritos sobre a universidade. São Paulo: Unesp, 2001.

COSTA, Manoel Baltasar Baptista da. Agroecologia no Brasil: histórias, princípios e práticas. 1 ed. Rio de Janeiro: Expressão Popular. 2017.

FREIRE, Paulo. Extensão ou Comunicação? 9a edição. Rio de Janeiro: Paz e Terra, 1985.

GOMES, Paulo César da Costa. Espaços públicos: um modo de ser do espaço, um modo de ser no espaço. In: CASTRO, Iná Elias de; GOMES, Paulo César da Costa;

CORRÊA, Roberto Lobato. Olhares geográficos: modos de ver e viver o espaço. Rio de Janeiro: Bertrand Brasil, 2012, p.19-41.

RUFINO, João Victor Pequeno; SILVA, Mariane do Rosário. Mapa das unidades de produção dos agricultores entrevistados e da FAF-UFRRJ-IM In: SILVA, Mariane do Rosário. Feiras Agroecológicas como Espaços de Diálogos de Saberes em Nova Iguaçu (RJ). Monografia (Graduação Licenciatura Plena em Geografia pela Universidade Federal Rural do Rio de Janeiro) Nova Iguaçu: UFRRJ, 2019. Mapa: 10,03 x 14,75 cm. Escala: 1:20000. Programa: Quantum Gis 3.4.

SOUZA, Marcelo Lopes de. O território: sobre espaço e poder, autonomia e desenvolvimento. In: CASTRO, I. E. (et al). Geografia: conceitos e temas. 2 ed, Rio de Janeiro: Bertrand Brasil, 2000, p. 77-116.

THIOLLENT, Michel. Metodologia da Pesquisa-Ação. 18 ed, São Paulo: Cortez, 2011.

Recebido em 25/03/2019.

Aceito para publicação em 30/05/2019. 